\title{
Teaching English as a Foreign Language (EFL) in Chinese Schools: The Case of Dongchang Middle School Using Schema Theory
}

\author{
Naminse Eric Yaw ${ }^{*} \quad$ Zhu Fangyang Zhan Jingang \\ School of Economics and Management, Beibu Gulf University, No. 12, Binhai Avenue, Qinzhou 535011, \\ Guangxi Province, P.R. China \\ ${ }^{*}$ E-mail of corresponding author: yawric@yahoo.com
}

\begin{abstract}
This empirical study applies the schema theory English writing teaching in a middle school in China according to the new curriculum standards. This study mainly seeks to address two issues: i). Does the application of schema theory in teaching English writing in middle school effective? ii). Compared with the traditional teaching of English writing teaching methods, can middle school students' English writing method based on schema theory be more efficient?The methods used in this study are known as the literature analysis and experimental research methods. This paper analyzes the current situation of middle school students' writing level and teachers' English writing, based on the schema theory of education.A survey was conducted as a teaching experiment for about two months in two parallel classes in Donchang Middle School. The controlled class used the traditional teaching method, while the experimental class used the teaching method based on schema theory. After about a period of the experiment, the two classes were post-tested and data collected, analyzed and conclusions made. The findings show that the Schema Theory used in English teaching can effectively improve the writing ability of students and enhance their confidence in English writing. Therefore, it is recommended that the schema theory should be used as a method of effectively teaching English writing.
\end{abstract}

Keywords: English education, schema theory, teaching and learning, Middle School, Dongchang, China

DOI: $10.7176 / \mathrm{JEP} / 11-15-03$

Publication date:May $31^{\text {st }} 2020$

\section{Introduction}

The teaching and learning of English language in China has been a challenge for many years to both students and teachers. Most often, students seem to rely on rote learning; that is by memorizing what is written in the English textbooks, while non-native English teachers also find it difficult to help the students understand basic concepts in English. One of the educational theories called Schema theory, which was put forward in the 19th century has in recent times become overwhelmingly prevalent in the teaching and understanding of the second language in most Chinese middle schools.

Many scholars have applied schema theory to English reading and listening, which appears to have had positive impact on both students and teachers.

However, the application of schema theory of writing has been deficient in particular in some middle schools in China. In addition, the comprehensive language ability of English includes listening, speaking, reading and writing skills, and writing plays an important role in expressing and communicating information. According to Liu (1999) the level of writing can tell an individual's language accomplishment. Moreover, the overall goal of English teaching and learning as a foreign language in China is to cultivate students' comprehensive language application ability under the curriculum standards for middle schools' English language.

English writing is the comprehensive reflection of students' English level, which can objectively reflect students' comprehensive usage of language ability. Hence, it is observed that the development of English writing skills is an essential part of education in middle school English teaching and learning.

According to the implementation of the new curriculum standards for the stage of elementary education in China, the situation of most students with low English writing skills is gradually emerging. For instance, many teachers do not focus on the teaching of writing, but use traditional translation methods to teach writing in middle schools. Furthermore, English learning has mainly been focused on the memorization of vocabulary and grammar, ignoring the other skills of language learning. Eventually, the writing skills of students appear to decline. In the midst of the busy teaching tasks, there is almost no time left to guide students in writing. Therefore, teachers often ask students to recite large volumes of model texts and rely on themselves to digest them, and therefore most students do not know how to write when they take English examinations, which then reflects a single teaching method being applied. In view of this situation, this paper finds that the new curriculum standards can be combined with schema theory to guide middle school students in English writing. It is believed that the schema theory in combination with cultural schema and the consolidation of formal schema has great guiding principles towards effective teaching of English writing in middle schools, and thereby help to meet the requirements of the new 
curriculum standard of middle school English writing in the country. Therefore, this paper analyzes the requirements of the new curriculum standards and the contents of schema theory, and combining the two to give priority to the application of schema theory in middle school English teaching and learning so as to improve students writing skills.

\section{Literature review}

\subsection{Meaning and development of Schema Theory}

The concept of schema theory was initially introduced into the fields of education and psychology through the work of the British psychologist (Bartlett, 1932). This theory was further developed by the educational psychologist Anderson (1979) and the concept has been used extensively by several scholars.

It is also believed that Kant (1781) firstly proposed the schema theory and it has several definitions. Some of the definitions are as, some of them are as follows:

According to Kant (1781), this is a representation of a universal procedure of the imagination in providing an image of a concept, entitled as schema of the concept. Kant further used the concept of schema to explore the origin of knowledge. For Rumelhart (1980), schema is a data structure used to represent common concepts stored in memory. All knowledge is packaged into units. These units are the schemata. In these packages of knowledge, apart from the knowledge itself, information is given about how is knowledge is used.

Carroll (2000) states that a schema is a higher level of knowledge structure that reflects expectations of a specific range of reality and will guide the processing and understanding of stimulus information.

Schema is defined as one of the ways that knowledge is represented. Plainly speaking, a schema is an organized knowledge structure like a network. It supposes that the network consist of 'nodes' and 'linkages', and the nodes consist of cognitive units and the 'linkages' represent the relationship between these cognitive units (Brown, 1994).

\subsection{Key features and functions of schema theory}

From the development history of schema, the theory possesses the characteristics of generalization, knowledge and comprehensiveness, which also determine the function of the schema. Generalization means that the knowledge in the schema is summarized from various kinds of specific knowledge, and with general meaning.

The knowledge presented by schema can be the meaning of a word, the composition of a sentence, the cultural background, the ideological point of view or the theoretical meaning.

Comprehensiveness means what the schema presents about all the knowledge of people, which comprises knowledge modules according to different types. In order to obtain higher-level diagrams, it can be combined to form a comprehensive schema according to different types of schemas. For instance, the application of linguistic schema, cultural schema and formal schema is the comprehensive manifestation of schemata in writing.

In brief, the basic principles of schema theory include the following:

- Schema is an abstract mental structure

- People build on those structures to understand the world.

- People use schema to organize current knowledge and provide framework for future understanding

- They are an effective tool for understanding the world, the use of schema makes the automatic processing an effortless task in teaching and learning environment

- People can quickly organize new perceptions into schema and act effectively without effort.

- When learners build schema and make connections between ideas, learning is maximally facilitated and it is optimally made more meaningful.

- Prior knowledge is important schema and it is a prerequisite for the understanding of new information.

- Internal conflicts may arise when new information does not fit with existing schema.

- People's schema have a tendency to remain unchanged, even in the face of contradictory information. In other words, it is difficult to change existing schemata. People tend to live with inconsistencies rather than change from deeply rooted mental structure.

In the teaching of English language, schema theory is critically relevant in the mastering of listening, reading, and writing skills.

The functions of schema theory are also as follows:

- Influencing our attention and interpretation of information, which can provide background knowledge to help understand.

- Schema can also allow us to go beyond given information to make predictions and inferences.

- The theory also has the function of transferring. There is no doubt that applying the existing schema to the new situation can enable people to acquire new knowledge. 


\subsection{Classification of the schema theory}

- The use of schema theory in teaching, according to researchers has been divided into linguistic schema, cultural schema and formal schema.

- Linguistic schema refers to the background knowledge related to the content of the article, which mainly includes the ability of learners to master and use vocabulary, grammar and idiomatic expressions, and it forms the basis and premise of English writing. According to Carrel and Eisterhold (1983) they believed that for English learners, they should acquire the ability to have certain language knowledge and use the language in order to activate the corresponding schema structure. Therefore, language learners must have a rich vocabulary and be proficient in grammar rules and sentence patterns. It is only then that can learners choose appropriate vocabulary and sentence patterns according to the topic to write articles with distinct themes. Therefore, the formation of linguistic schema plays an important role in further activating language knowledge.

- Cultural schema, on the other hand refers to the knowledge structure established by cultural knowledge other than text, including local customs, historical background and other content (Cook, 1989). There is no doubt that culture is very helpful for people to understand the discourse of learning English language. Learners therefore tend to think more in their mother tongue because of the differences between Chinese language and Western cultures, so it is difficult to meet the standards of language writing. Thus, establishing the necessary cultural schema is very important to language learners.

- Formal schema, means the knowledge of text structure, covering knowledge of grammar and text (Minsky, 1975). It is not a form inherent in the mind of learners, which is a structure that is accumulated through reading activities for many times and is established under the guidance of teachers. After establishing such a schema in the minds of learners, it will help improve greatly the writing skills of learners.

\section{How to effectively teach English writing skills}

\subsection{Understanding of English writing}

Writing is a skill, but it does also involves a series of complex processes, which is oftentimes regarded as the last language skill to be learned. According to Gould, Dianne and Smith (1989), writing is an act of creativity because it requires individuals to explain or understand something. Writing is a form of social conversation, and the process of writing mainly depends on information stored in the writers' minds.

\subsection{The components of English writing}

The skills of writing in English require a higher level of grammar, vocabulary, sentence patterns, and writing techniques. The writing process needs to pay attention to three main elements. First, the content of the point, that is to say, to understand the topic, then choose the appropriate materials to determine the main idea of writing the article. Second, writing should have a clear thinking, to take care of the beginning and the end, to inherit the middle of the article and the division of paragraphs reasonably. Finally, the language must be correct. Hence, the selected words should be clear, accurate, and vivid in meaning, grammatically correct, and consistent with the English language expression during the writing process.

\subsection{English writing teaching methods}

There are various methods used to ensure that English writing skills is enhanced. One of such methods is known as the product-based approach. This is one of the most traditional approaches used in teaching English writing, which is based on the theory of behaviorism. Thus, the teaching method is the process which stems from stimulus to reaction. This writing process focuses on the theory of teach, and develops the techniques and writing skills, then it provides model essays, analyze rhetorical forms and structural patterns, and at last carry out model essay imitation. It stresses writing skills results and the precise development of grammar and semantics (Klein, 1986), which is beneficial to beginners to understand the basic language forms, and also helps teachers and students to analyze and practice using multiple texts.

The second method is called the process-based approach. This is also referred to as the process-oriented writing method. In this method, teachers give priority to the design of writing activities and the guidance of writing approaches to enable students design articles and write their outlines. In general, the process-based writing method consists of the following steps, according to Picas, (1982):

- Pre-writing preparation: students are required to design, write outlines and prepare to write the materials.

- First written draft: this involves translating the result of conception into written blank according to the outline.

- Revision and modification: it can be divided into two parts, namely students revise it with each other and teachers modify them. From the main idea to the description, details of the article and the choice of words needs to be rectified. Moreover, individual guidance should be given to students who will be in need of 
help.

- Rewrite the final draft: this entails rewriting the final draft according to the correction of the previous section.

- The article revised again: the teacher revises the student's article again and writes the comments.

The writing process after these links is more substantial, which makes the activities between students and teachers more direct. This process-based method in teaching English writing fits well for teaching of writing habits and skills among middle school students.

The next method is Genre-based approach. This pays more attention to the content of the writing materials and appraising the materials to be processed. The focus is mainly on teaching how to help students collect writing materials and enrich the content of their writings, instead of just teaching the skills and methods of writing. The steps of the genre-based approach are as follows:

- Pre-writing preparation: In this instance, students are made to read the relevant materials to find out the arguments with relevant topics, analyze and sort out the materials.

- First written draft: It involves sorting out the analysis, extracting the outline, and writing it into essay in accordance with the collected materials.

- Revision: This is separated into two parts; one is to highlight the challenges in the content and structure of the article, that is to say, whether the grammar, punctuation and vocabulary are used correctly or not.

This kind of teaching method can make students become more open to ideas, enrich their writing skills and content, and enable them write persuasive articles that are full of vitality.

\section{New English curriculum standard}

\subsection{Requirements of the new English curriculum standards of Middle Schools for English writing in China}

It the Compulsory Education English Curriculum Standards (2011 Edition), new contents and standards are put forward for the cultivation of five goals: language knowledge, emotional attitudes, learning strategies and cultural awareness. The four basic skills of listening, speaking, reading and writing are still the main skills of language training in China, which are indispensable. The five-level goal is taken as an example to see the writing requirements of the new English curriculum standards according to the learning needs and psychological development of middle school students in China.

Table 1. Requirements of the new English curriculum standards

\begin{tabular}{|c|c|c|}
\hline Rank & Skill & Objective statements \\
\hline \multirow{5}{*}{$\begin{array}{l}\text { Level } \\
\text { Five }\end{array}$} & \multirow{5}{*}{ Writing } & 1. Be able to collect and prepare materials according to writing requirements. \\
\hline & & $\begin{array}{l}\text { 2. Be able to draft essays, text messages by oneself and so on and modify them } \\
\text { under the guidance of teachers. }\end{array}$ \\
\hline & & $\begin{array}{l}\text { 3. Be able to use common connectives to represent the order and logical } \\
\text { relationships. }\end{array}$ \\
\hline & & 4. Be able to briefly describe people and/or events. \\
\hline & & $\begin{array}{l}\text { 5. Be able to write simple paragraphs or operation instructions according to } \\
\text { schemata or tables. }\end{array}$ \\
\hline
\end{tabular}

\subsection{Challenges of teaching writing under the new curriculum standard in Middle Schools}

With the progress of the new curriculum reform, there are some new requirements of the cultivation of skills in teaching English under the new curriculum standard. While attention need to be paid to writing, the development of this skill is gradually being ignored in teaching English in middle schools in China. When it comes to the content of writing, some English teachers just accentuate by reciting the essays unilaterally, imitating it appropriately, which lacks systematic writing guidance. Beyond that, writing is often ignored by many students, resulting in more points being lost during examinations. Eventually, the writing competence of students is neglected, and it is impossible to meet the requirements for writing skills in the new curriculum standards set out to achieve.

\subsection{Challenges faced by students in learning English writing}

English writing is meant to check the ability of students to use enough vocabulary and grammar to form words and sentences, organize paragraphs and layouts. However, the writing proficiency of most students is still weak and there are many challenges they face such as:

- Weakness for writing foundation: for example, one of the most prominent challenges of students is poor vocabulary, grammatical misuse and spelling errors. The ability to master basic sentence patterns and use English expressions flexibly is still very poor among middle school students because of the interference of native language

- The poverty of writing content: It can be seen that most of the students have no depth of content, and the words used in writing are also the simplest from usual practice and examination. Hence the content often 
appears monotonous and plain.

- Inadequate writing cohesion: the contents of most articles of many students are just a pile of simple sentences, and which lack the necessary transition and coherence between sentences and paragraphs, which affect the transmission and expression of information, leading to the ambiguity.

\subsection{Challenges teachers face in teaching English writing}

During the teaching process, some teachers only train students on how to become qualified examination takers so as to achieve the purpose of entrance examination, but the integrity of teaching writing as a skill is usually overlooked.

There is therefore the need to take the input of language seriously, and do not neglect the output of language. The knowledge of English language should be stressed by teachers during teaching. Teachers usually decompose texts into many minor language knowledge points, thus destroying the integrity of the text, and also cause the students to neglect writing and stick to grammar and vocabulary during the learning process. Moreover, some teachers also tend to ignore that language output is the key to improving English learning ability in the teaching process.

The lack of training for systematic writing and detailed writing teaching plans is also another challenge English teachers at middle schools in China face. Language input of teachers runs through the whole teaching process, for which the teacher attaches more importance to the explanation and in-depth part of language and grammar points in the process of preparing lessons, while the students' language application skills might not have been improved drastically. Besides, the teaching plan of English writing is often put at the secondary level, so much as not in-depth analysis of relevant knowledge for writing on the examination. For the development of writing skills, teachers only ask students to memorize model essays and selected sentences. This situation needs to be avoided in order to improve the teaching of English writing in middle schools in China.

\section{Materials and method}

\subsection{Study area}

Donchang Middle school is the place chosen for the conduct of this study. It is particularly selected due to its strategic location in the semi-rural area within Qinzhou in Guangxi Province of China. Dongchang Town is under the jurisdiction of Qinnan District, Qinzhou City, and Guangxi Zhuang Autonomous Region. It is about 28 kilometers away from the city of Qinzhou, 150 kilometers north of Nanning, the capital, and 3 kilometers away from Beibu Bay in Dongchang town. The middle school is located in Dongchang town, the coast of Beibu Gulf in the southeast of Qinzhou City. It is across the sea from Xichang town, Hepu County, Beihai city in the east, adjacent to Sanniang Bay management district in the south, connected to Qinzhou port in the west, and connected to Nali town and Shabu town in the north. Dongchang town itself is an important hinterland of the Qinzhou port economic and technological development zone. As at the end of 2010, Dongchang town had jurisdiction over seven communities, eighty-eight natural villages, one hundred and fifteen village groups, with a total population of 21,642 in 2017. It also has a total land area of 179.3 square kilometers, a forest area of 138,544 acres, and a coastline of 42 kilometers. The town is popular for the cultivation of sugarcane in Qinzhou. For example, in 2006, the sugarcane planting area of Dongchang town was about 30,180 mu, which is one of the main sugarcane areas in Qinnan District. Forestry focuses on the development of wetland pine and fast-growing eucalyptus. The aquaculture area is 21,210 acres, of which the shrimp aspect of the aquaculture area is more than 6,000 acres.

\subsection{Source of data}

The study collected data from November to December in 2019, using questionnaire and teaching observations. Pre-test and post-test were conducted as well. In order to help determine the writing tasks required in this study, the pre-test topic was 'describe yourself and your family', while the post-test topic was 'write a letter to your foreign, describing your new school'. The students were made to complete both the pre-test and post-test English writing in a class, using another class as control. The comments of the students were taken, using entrance examination of English writing expression as the scoring criteria.

\subsection{Sampling procedure}

Two classes from the senior Grades were selected from the Donchang Middle School. The English teacher then chose class A as control class and class B as observation/experimental class, with a total of 110 students. The average English scores of the two classes were basically the same. A comparative study was used, since it required to examine three key variables: independent variable, dependent variable and the control variable. The independent variable refers to two different teaching modes of English writing. That is to say, control class uses the productbased approach method and observation class used the schema theory training. The dependent variable means the English writing scores of students before and after, while the control variable referred to the total English class hours, English writing teaching hours, teachers, age of students and the original level of English writing were the 
same across board.

\subsection{Hypotheses}

In this study, two questions that needed to be addressed were: 1 . How does the use of schema theory at middle school to teach English writing effectively enhances the interest of students in English writing and learning. 2. Does the teaching of English writing skills based on schema theory more effective, compared with the traditional teaching approach?

The above two questions form the hypotheses of the study, and the findings confirm or reject the hypotheses based on the data before and after the study.

\section{Results and discussion}

\subsection{Gender of participants}

Table 2 below shows the gender difference of participants who took part in the study. The participants were Middle school students in Dongchang of Guangxi province. This was made possible with support from one of the school's English teachers. The results show that there were 42 male students $(38.18 \%)$, and 68 female students $(61.82 \%)$ involved in the study.

Table 2. Gender of participants

\begin{tabular}{|c|c|c|}
\hline Gender & Number of participants & Percentage \\
\hline Male & 42 & 38.18 \\
\hline Female & 68 & 61.82 \\
\hline Total & 110 & 100 \\
\hline
\end{tabular}

\subsection{Data analysis}

The students of the two classes were made to write an essay of 60 words with 'My best teacher' before the experiment, which is graded according to the scoring criteria for English composition of middle school entranced examination. After the writing test, students in the two classes got an average score. Next, the two classes took another test on the topic: 'My first day in school' and the average score of them were made based on the scoring criteria. In Table 1 below, it is realized that the writing levels of the two classes are comparable before training. Further still, the scores of the two classes have improved after the experiment/observation. However, the results of the experimental class have greatly improved compared with the control class.

Table 3. Comparison of results between control class and experimental class

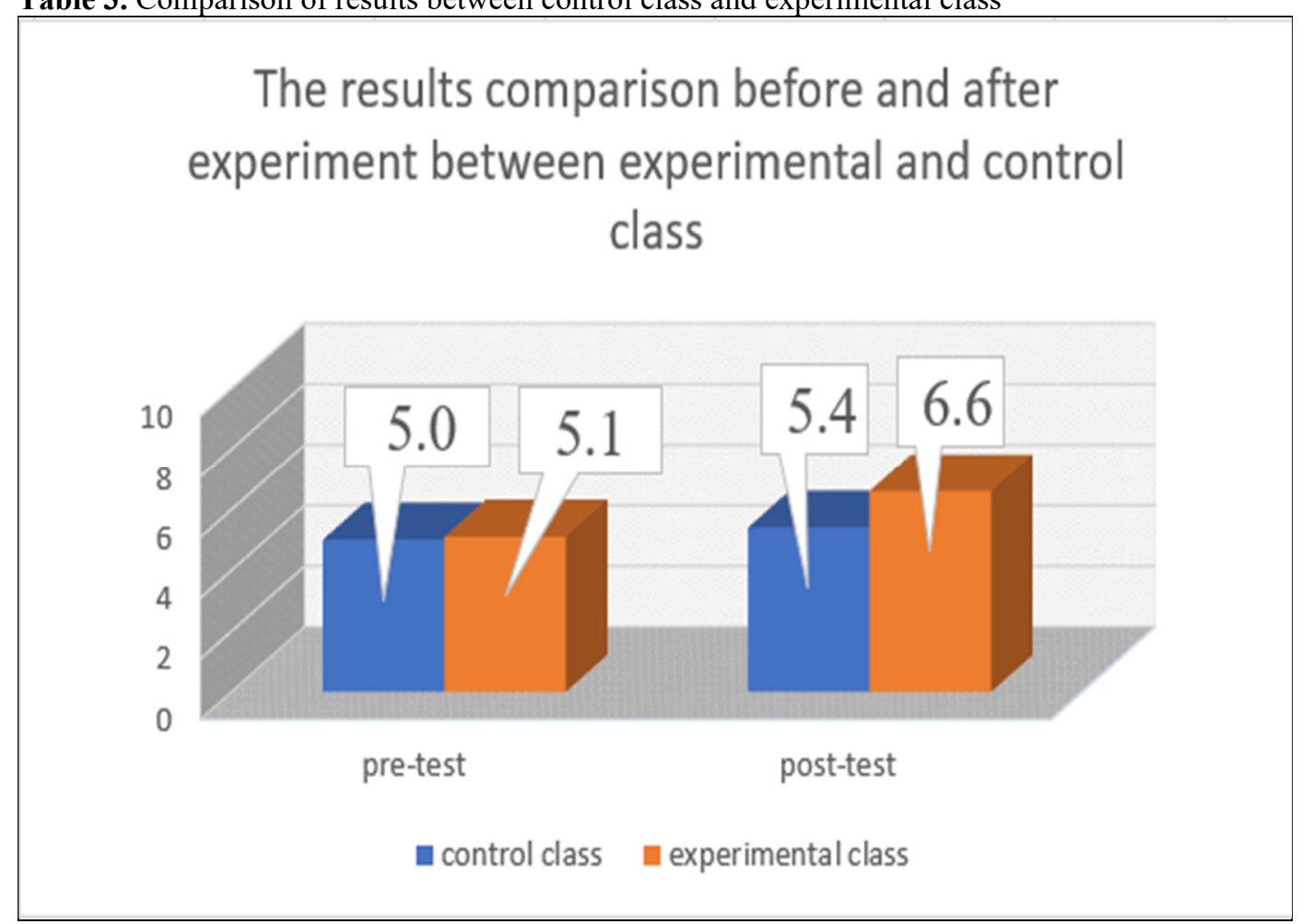

Therefore, through the comparison of student performance with charts in applying schema theory, it greatly improve the effect of teaching English writing skills and plays a great role in improving the writing abilities of students. This also helps to achieve the requirements of the new curriculum standard. It is therefore important for 
English teachers to pay attention to the use of schema theory.

\subsection{Reading of articles and accumulation of linguistic schema}

Language learning has always underlined input and output, and teachers have attached great importance to the input process, such as a lot of vocabulary, phrases, sentence patterns, and grammar being constructed by students. However, the input is often fragmented and stored in the minds of students. Therefore, students will feel that there is no word available and nothing to say when they need to write. Through the experiment, when students meet related topics through reading of articles, they are able to apply what sentence patterns are more suitable for expressions. This shows that in the learning process language schema is formed.

\subsection{Accumulating Abundant Materials and Improving Cultural Schema}

The new curriculum standard has put forward the goal of cultivating in the students at middle schools cultural awareness and communication skills to improve their language ability. The content of cultural awareness includes cultural knowledge, and cultural communication ability, which enables students to use language properly. In practical English learning, students lack the accumulation of cultural knowledge, which leads to a lack of cultural schema. Therefore, this can affect students in the use of language knowledge. Middle school students should therefore give more attention to the origin of vocabulary, specific occasions of usage and different Chinese cultural norms while learning English writing as a skill. The accumulation of knowledge will help improve cultural awareness and establish the needed cultural schema.

\subsection{Difference between genres and building formal schema}

Middle school students will find that there are different types of articles for reading in English to improve their skills in reading, listening, speaking and writing in particular. When they are able to understand the text structures of such articles, then they will accumulate knowledge of text structure and promote the formation of formal schema. In the process of learning English writing, it will be of great help to improve on writing skills through mastering the methods of discourse analysis, forming discourse patterns and strategies of different genres, and forming formal schema of different genres.

\subsection{Strategies to solve challenges affecting teachers' use of schema theory}

It has be found out that the single English writing teaching method is one of the reasons for the low level of writing among students in middle schools in China. Through analysis, schema theory combines the advantages of English writing teaching method, that is, product-based approach, process-based approach and genre-based approach. It can use schema theory to train students to acquire writing skills from the three links before, during and after writing, and form effective writing teaching methods, and strengthen the construction of schema theory, which will then help solve the challenges faced by teachers in delivering lesson on English writing.

\subsection{Improvement in English vocabulary and sentences training}

From the study, it is advisable for English teachers to train students on how to express their thoughts with the words, phrases and sentence patterns learned in the text before writing them out so as to improve the writing skills of the students. Therefore, in the initial stage of English teaching, students can activate their accumulated language knowledge through vocabularies and sentences training activities such as phrases construction, sentence patterns conversion, and sentences rewriting. These pre-writing training activities can effectively help to develop the thinking ability and language application ability of students.

\section{Conclusion and future research outlook}

In the present study, through a theoretical and empirical analyses, it has been found out that the schema theory has a much positive effect on the teaching of English writing skills in China. Thus, the schema theory can significantly help students at middle school to improve their English writing abilities.

Furthermore, teachers should fully study and understand the important linkage between schema theory and the teaching of English writing skills in middle schools in China. The effective use of the concepts and forms of schema theory in English writing will fully embody the positive effect of middle school English writing. When there is focus on vocabulary and sentence writing training to activate language schemas of students, emphasizing training on writing skills in various topics to build new cultural schemas and cultivating discourse to build writing ability and consolidate formal schemas will lead to much improvement in performance of students in English.

Teachers need to also ensure that students have sufficient and understanding of the language input, not only to strengthen basic knowledge of English and language skills, but also to help students actively construct knowledge patterns such as genre and cultural background. The teaching methods of teachers should also be improved through the strengthening of interventions in the writing process, guiding cooperative learning and teaching writing strategies. At all times, students should be guided by their teachers to recognize their learning 
styles and master the most suitable writing learning strategies.

In spite of the fact that the results of this study are important, there are were some few limitations. Therefore, future research should widen the scope of the study to include more middle schools in Guangxi Province, as well as the number of classes.

\section{Acknowledgments}

This paper received financial support from the 2017 Guangxi Science and Technology Base and Talents Project of Beibu Gulf Marine Resources and Industrialization Development and Utilization Innovation Talents Training Demonstration Base Construction of Beibu Gulf University (Grant No. Gui Ke AD17195082), as well as the Beibu Gulf Ocean Development research Center.

The authors are grateful for the support, and also express their appreciation to persons who assisted in the data collection for the study.

\section{References}

Anderson R.C. (1979). Schooling and the Acquisition of Knowledge. Instructional Science, 207-211

Bartlett, F. C. (1932). "Remembering," Cambridge University Press, Cambridge.

Brown, H. D. (1994). Teaching by principles: An Interactive Approach to Language Pedagogy. New Jersey: Prentice Hall Regents.

Carrel, P.L. \& Eisterhold, T.C. (1983). Schema theory and EFL reading pedagogy.

Carroll, D. W. (2000). Psychology of Language. Beijing: Foreign Language Teaching and Research Press.

Cook, G. (1989). Discourse in Language Teaching: A Schema for Teacher Education. Oxford: Oxford University Press.

Gould, E., Diyanni, R. \& Smith, W. (1989). The Act of Writing [M]. New York: Random House.

Kant, I. (1781). Critique of Pure Reason ( $2^{\text {nd }}$ ed.). London: Macmillan.

Klein, W. (1986). Second Language Acquisition, Cambridge, Cambridge University Press.

Liu, R. (1999). Western Linguistics. Beijing: Foreign Language Teaching and Research Press.

Minsky, M. (1975). A Framework for Representing Knowledge [A]. In the Psychology of Computer Vision [C]. Ed. Patrick H. Winston. New York: McGraw-Hill.

Picas, A. (1982). Teaching English Writing [M]. London: Macmillan

Rumelhart, D. E. (1980). Schema: The Building Blocks of Cognition. In R. J. Spiro, B. C. Bruce and W. F. Brewer (eds.). Theoretical Issues in Reading Comprehension. New Jersey: Lawrence Erlbaum Associates. 33-58. 